\title{
STRUCTURAL DIVERSITY AND BIOCHEMICAL AND MICROBIOLOGICAL CHARACTERISTICS OF AFLATOXINS
}

\author{
Otto KETNEY $*^{1}$, Tita OVIDIU* ${ }^{*}$ Anca TIFREA* \\ * "Lucian Blaga” University of Sibiu, Faculty of Agricultural Sciences, Food \\ Industry and Environmental Protection, Sibiu, Romania
}

\begin{abstract}
Among all mycotoxins, Aflatoxin $\mathrm{B}_{1}$ (AFB1) is considered to be the most carcinogenic, and it has been classified by the International Agency for Research on Cancer in Group 1 of human carcinogen. It signifies a high hazard because it contaminates a diversity of agricultural products such as nuts and derivatives, peanuts/hazelnuts, grains, seeds, cottonseed, milk, dairy food. In milk AFB1 is metabolized to aflatoxin M (AFM1) which is 4-hydroxy derivative of AFB1, it is formed in the liver and excreted in the milk into the mammary glands of both human and lactating animals which have been fed with AFB1 contaminated diet. After the food contamination, one part of the aflatoxin B1 which was present in the food is eliminated through the milk. At the molecular level aflatoxin biosynthesis involves several levels of transcriptional and post-transcriptional control, so the main stages subsequent biochemical and genetic constituents of aflatoxin biosynthesis have been demonstrated recently. Recent studies over the last few decades have shown that the metabolism of AFB is an essential component of hepatocarcinogenic, however it was shown that AFB1 is metabolized by cytochrome P450 oxidised to intermediates and other metabolites Therefore, the biotransformation process may also lead to the formation of carcinogenic metabolites.
\end{abstract}

Keywords: mycotoxins, aflatoxin, milk, Aspergillus

\section{INTRODUCTION}

According to the European Union and to the World Health Organization, food safety is everyone's responsibility, starting from the food origin until it gets on the customer's table. The food can contain a number of chemical compounds with toxic effect that can influence consumers' health. Substances having toxigenic effect on milk and milk products include

${ }^{1}$ Correponding author. Mailing adress: University Lucian Blaga of Sibiu, Faculty of Agricultural Sciences, Food Industry and Environmental Protection, Str. I. Raţiu 7-9, 550012 Sibiu, Romania. E-mails: otto.ketney@ ulbsibiu.ro, otto_ketney@yahoo.com

Acta Universitatis Cibiniensis Series E: FOOD TECHNOLOGY

Vol. XVIII (2014), no. 2 
alfatoxins which are produced by means of biosynthesis of Aspergillus species, being developed on a substrate which can produce illness to those/people consuming the product.

Two recent research (Kensler et al., 2011; Wu et al., 2014), were limited at adverse effects on human health of exposure to aflatoxin. These tackle the mechanisms of toxicity to aflatoxin contamination body and related diseases. So to protect the health of humans and animals, over 100 nations have established maximum tolerable levels for aflatoxin in food $(\mathrm{Wu}$ and Guclu, 2012). These include and the European Union which established the level of AFM1 in milk consumption levels $\left(0.05 \mu \mathrm{gL}^{-1}\right)$ (European Union 2006).

Data according to which a large number of mycotoxins (over 200 species have been identified) exist in nature, is cited in literature (Richard, 2007; Creppy, 2002; Logrieco et al., 2002; Desjardins, 2006). Basically, there are no known areas around the globe but it is estimated that $25-60 \%$ of cereals and animal food throughout the globe are contaminated with known mycotoxins.

In order to reductions mycotoxins exist a number of ways such some physico-chemical methods shows advantages ,however in literature are still natural approach which involve heat treatment (Park, 2002), UV light (Ketney et al., 2010) or ionizing radiation (Herzallah et al., 2008) unfortunately they are still not applied on an industrial scale.

\section{STRUCTURAL DIVERSITY}

The term "Mycotoxin" has Greek origin and it is a natural toxin produced by

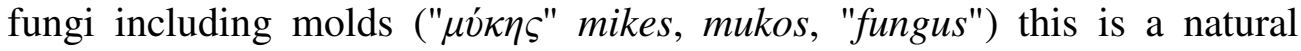
toxin produced by fungi include molds, mostly fungi are aerobic (use oxygen). The term was introduced in 1962 by British researchers (Blount, 1961).

Over 100 species of fungi have been shown to produce mycotoxins such naturally associated with the development of various diseases in animals and humans, although from the point of view of toxigenic fungi and their spores are present everywhere, mycotoxicosis are primarily a problem in areas where the precipitation, relative humidity and temperature favor fungal growth and mycotoxin production.

From group of mycotoxins, aflatoxins are toxic secondary metabolites which are mainly produced by Aspergillus species, Aspergillus flavus and Aspergillus parasiticus (Machida et al., 2005; Peiwu Li et al., 2009) being found throughout the world, and they are present both into the ground and in the air (H. K. Abbas et al., 2005; Klich, 2002) they usually contaminate a large variety of food / feed in tropical and sub-tropical regions (Yunus et al., 2011).

Acta Universitatis Cibiniensis Series E: FOOD TECHNOLOGY

Vol. XVIII (2014), no. 2 
On the basis of genetic and physiological morphological criteria, Aspergillus Flavus can be divided into two types taxonomy. S-type strains produces numerous small sclerotia (diameter less than $400 \mu \mathrm{m}$ ) and high levels of aflatoxin B series. L-type strains produce fewer large sclerotia and on average have a lower level of aflatoxins (Ehrlich et al., 2003).

\section{CHARACTERISTICS OF MYCOTOXINS PRODUCED BY ASPERGILLUS SPECIES}

\section{Structural characteristics of aflatoxin B group (B1 and B2)}

From the structural point of view the most common aflatoxins are AFB1, AFB2, AFG1 AFG2, AFM1 and AFM2, the term "B" and "G" refers to the colors blue and green products fluorescence UV light on TLC plates while the number 1 and 2 show the respective minor and major compounds (Bennett, 2003). However aflatoxin B1 (AFB1) is a highly toxic compound with a lethal dose $\left(\mathrm{LD} 50=1-50 \mathrm{mg} \mathrm{Kg}^{-1}\right)$ for most species, however is toxicity critical (LD50 $<1 \mathrm{mg} \mathrm{Kg}^{-1}$ ) for some highly sensitive species, such as rats (Kumar et al., 2012; Fiala et al., 2011; Fetaih et al., 2014; Shyamal et al., 2010) , rainbow trout (Arana et al., 2014; Alinezhad et al., 2011) and poultry (Raphaël et al., 2014; Magnoli et al., 2011; Chen et al., 2013; Hussain et al., 2010; He et al., 2013; Wan et al., 2013). The toxic effects of AFB1 can be differentiated according to the level and duration of exposure to aflatoxin (Diaz et al., 2011)

Aflatoxins are fat-soluble compounds and are readily absorbed from the site of exposure, usually through the gastrointestinal tract and respiratory tract (Larsson and Tjälve, 2000; Agag, 2004). Contamination can be done in two major ways (a) ingestion of food contaminated with aflatoxin or aflatoxin ingestion or ingestion of aflatoxins in animal feed carried in milk and milk products (Agag, 2004), (b) by inhaling dust of aflatoxins in especially AFB1 in contaminated food industries and factories (Ali et al., 2013).

\section{Structural characteristics of aflatoxins in group $M\left(M_{1}\right.$ and $\left.M_{2}\right)$}

Biochemically speaking, Aflatoxin $\mathrm{M}_{1}$ (AFM1) is the compound 4-hydroxy AFB1, which is formed in the liver and excreted in the milk in the mammary glands of lactating both human and animals that were fed with contaminated AFB1 food (Fallah et al., 2009; Gürbay et al., 2010). Action level for aflatoxin $B_{1}$ is 20 parts per billion for dairy cows feed. Recently Battacone et al. (2003) observed that there was a linear relationship between dose AFB1 and AFM1 excretion in sheep milk. In general, it is believed that about 1-3\% aflatoxin B1 present in feed is eliminated as AFM1 in milk these values depend on the animal, the milking type and on many other factors. After stopping the consumption of food containing AFB1 must pass 72 hours

Vol. XVIII (2014), no. 2 
should pass in order for the aflatoxin concentration to be reduced to undetectable levels (Bilandžić et al., 2010).

Given these facts/given the above mentioned facts AFM1 was classified in group 1, regarding its risk (carcinogenic to humans) by the International Agency for Research on Cancer (IARC et al., 2002).

The Identification of AFM1 was made for the first time with layer chromatography (TLC) on extract of milk in 1964. Therefore, scientists such as De Iongh et al. (1964) showed by TLC a blue-violet fluorescent compound which had lower Rf value that AFB1. These chromatographic results have revealed that during the lactating period, AFB1 bio-converted to another toxic compound called by Allcroft et al. (1966) "toxic milk" which was later assigned a name and namely "aflatoxin M". Several chromatographic studies in various solvent systems have indicated that this "toxic milk" contains two fluorescent components, a blue-violet to purple Rf 0.34 , and a lower Rf value, that is 0.25 . Afterwards, aflatoxins were named, depending on the physical characteristics of fluorescence (in the length of wave $365 \mathrm{~nm}$ ) (Klich, 2007).

AFM1 determination is made by different techniques, the most common are thin layer chromatography (TLC) (Kamkar, 2006; Fallah, 2010; Carvalho et al., 2012), high performance liquid chromatography with mass detection (Huang et al., 2014; Han et al., 2010; Campone et al., 2013), electrochemical detection (Micheli et al., 2005; Rameil et al., 2010; Nguyen et al., 2013; Paniel et al., 2010) and chemiluminescence (Kanungo et al., 2011; Gan et al., 2013; Sarter and Zakhia, 2004; Vdovenko et al., 2014; Ping Li et al., 2014). Nevertheless the determination of AFM1 most often used international standard ISO 14501:2007 which is based on fluorescence or detected by mass spectrometry (Cavaliere et al., 2006; Afshar et al., 2013 ;Hashemi et al., 2014; Wang et al., 2012; Magnoli et al., 2011; Huang et al., 2014).

AFM1 is relatively stable milk products and is not affected by pasteurization (UHT or techniques) or cheese processing (Kav et al., 2011). Considering the fundamental role of milk and milk products in human nutrition, especially for children, this AFM1 in dairy products is considered a significant risk to food safety and public health (Cucci et al., 2007).

\section{BIOSYNTHESIS}

Aflatoxin biosynthesis is a complicated involving several process, this process involves some levels of transcriptional and post-transcriptional control (HK Abbas et al., 2009; Chanda et al., 2009; Georgianna and Payne, 2009; Schmidt-Heydt et al., 2009). At a molecular level, the main

Vol. XVIII (2014), no. 2 
biochemical steps and genetic constituents f aflatoxin biosynthesis have been demonstrated recently (Yu, 2003; Bhatnagar et al., 2002).

The process is done in a similar way for several toxic secondary metabolites produced by fungi, aflatoxins are synthesized from polyketide molecules where condensation of ethyl esters produced from intermediates of $\beta$-ketopoly-thiols. The chain biosynthesis pathway is initiated by acetyl CoA and malonyl-CoA being an additional source of carbon.

Cleveland et al. (2003); Yabe and Nakajima (2004); Yabe et al. (1999) assigns a currently accepted scheme for the biosynthesis of aflatoxin which consists of the following steps: hexanoyl-initiating CoA biosynthetic pathway reaching the norsolorinic acid, norsolornic acid that is converted in two steps through the intermediate process of averantin, after which it turns into averufin.

Averufin next step involves opening biosynthetic of the averufin ring, followed by the dehydration sequence, epoxidation and epoxide rearrangement to form the ethyl hemiacetal-versicolorin A through the versiconal A and versicolorin B, Versicolorin A is converted to dimethyl sterigmatocistin, then sterigmatocistin. Sterigmatocistin last major intermediate in oxidoreductase. A methoxy group, which is common to almost all aflatoxins appears from donor S-adenosyl-methionine (SAM) catalyzed by S-adenosyl-methyl-transferase. Bifuran ring formation in versicolorin A, sterigmatocistin and AFB1 appears involving hemiacetal acetate ester hydrolysis of the acetyl group versiconal eliminating followed by ring closure. The oxidation process of the terminal hydroxyl group to an aldehyde, results from the hemiacetal structure. The biosynthetic scheme for aflatoxin B1 is presented in Figure 1.

\section{BIOTRANSFORMATION}

Studies over the last few decades have shown that the metabolism of AFB is an essential component of its hepatocarcinogenic and the biotransformation differences significantly contribute, depending on the species and interindividual differences in susceptibility to AFB1 (Eaton et al., 2001).

AFB1 is metabolized by cytochrome P450 (CYP450) in intermediates and other oxidized metabolites, including hydroxylated forms of aflatoxin M1 (AFM), aflatoxin Q1 (AFQ), and demethylated form of aflatoxin P1 (AFP) (Gross-Steinmeyer and Eaton, 2012). However, biotransformation can also lead to the formation of AFB1-exo-8, 9-epoxide (AFBO), which is a carcinogenic metabolite of AFB1 (David, 1994).

In general, metabolism or biotransformation of xenobiotics (foreign chemicals to the body) represent a process which aims to transforming the original molecules in more hydrophilic compounds readily excreted in the

Acta Universitatis Cibiniensis Series E: FOOD TECHNOLOGY

Vol. XVIII (2014), no. 2 
urine (kidney) or bile (liver). It has traditionally been conceptualized as a process which takes place in two steps known as Phase I and II, although some authors claim that this classification may not be supported and should be removed (David et al., 2005).

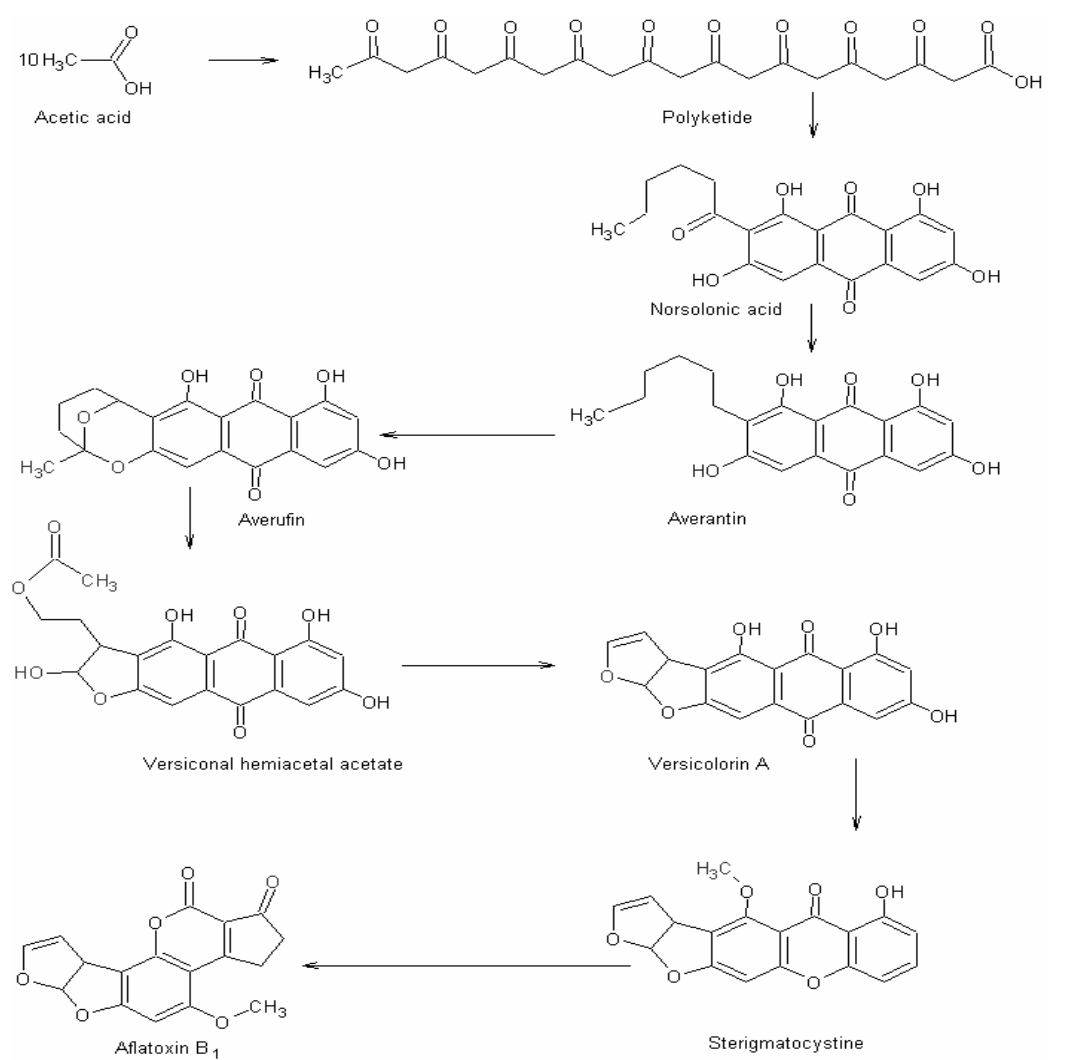

Figure 1 The biosynthetic scheme for aflatoxin B1 (Deshpande, 2002)

Animals also metabolize O-demethylation AFB1 by occurring AFP1 (Figure 2 ), which was subsequently detected in the urine in several animal species .AFP1was shown to be less toxic than AFB1.Through in vitro metabolism by liver microsomes of monkeys and humans these have produced major metabolites of AFB1, which contain hydroxyl groups, which are arranged in $\beta$ position of carbonyl groups of cyclopentanone ring in AFB1.

A general scheme for the primary metabolism of AFB1 is based on results obtained in vitro studies using liver subcellular fractions isolated from different animal species were also observed (Figure 2). Most of the metabolites in are less toxic than AFB1. From toxicologically most important intermediate toxic AFB1 form is AFB1-2, 3-epoxide and AFB1-8, 9-epoxid (AFBO). Yet there are two stereoisomers of AFBO (endo-and exo-)

Vol. XVIII (2014), no. 2 
and exo -AFBO is capable of reacting with $\mathrm{ADN}$ to produce preferentially adducts of N7-guanine.

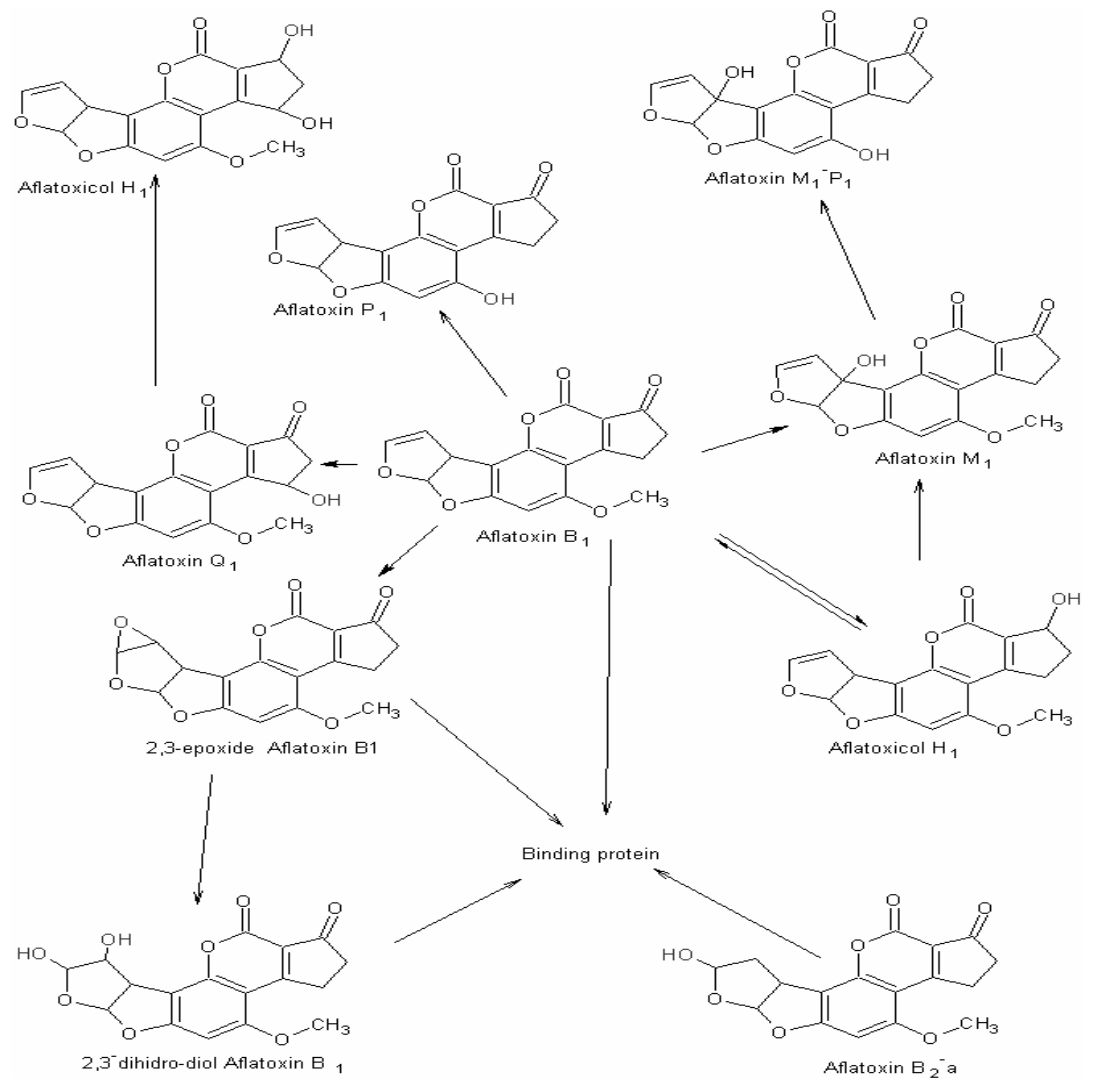

Figure 2 General scheme for the metabolism of aflatoxin B1 primary

(Deshpande, 2002)

The epoxide quickly hydrolysed to the initial state at AFB1-2, 3-dihidrodiol form, such AFB1-2, 3-dihidrodiol can be in accordance with the phenolate ion wicht is capable to forming Schiff bases with addition of an amino group of lysine (Figure 3)

An important characteristic in toxicity of AFB1 is metabolic activation by CYP450 of AFB1 to AFBO, which is an intermediate reaction which exert their toxicological effects through the binding of toxic cellular components, such as proteins, ADN and ARN (Guengerich et al., 1998). Multiple isoforms of cytochrome $\mathrm{P} 450$ are capable of AFB1 bioactivation, but evidence suggests that CYP3A4 and CYP1A2 are the main isoforms involved in human liver in this process (Kirby et al., 1993; Gallagher et al., 1994).

Vol. XVIII (2014), no. 2 
The most hydroxylated metabolites of AFB1 are formed from cytochromes P-450 which are AFM1, AFP1, AFQ1 and AFB2a (Figure 2). Additional metabolites that are generally formed in lesser amounts depending on different conditions, which include AFL and AFM1. These metabolites are considered as such detoxify AFB1 is more polar and thus more easily excreted. However recent studies show that the reduction of AFB1 by cytosolic reductase produce aflatoxicol (AFL), which is considered to be a detoxification product by some authors that, at least in the case of fish, it may be oxidized back to AFB1 by a microsomal dehydrogenase, thus increasing the half-life physiological of AFB1 (Troxel et al., 1997).

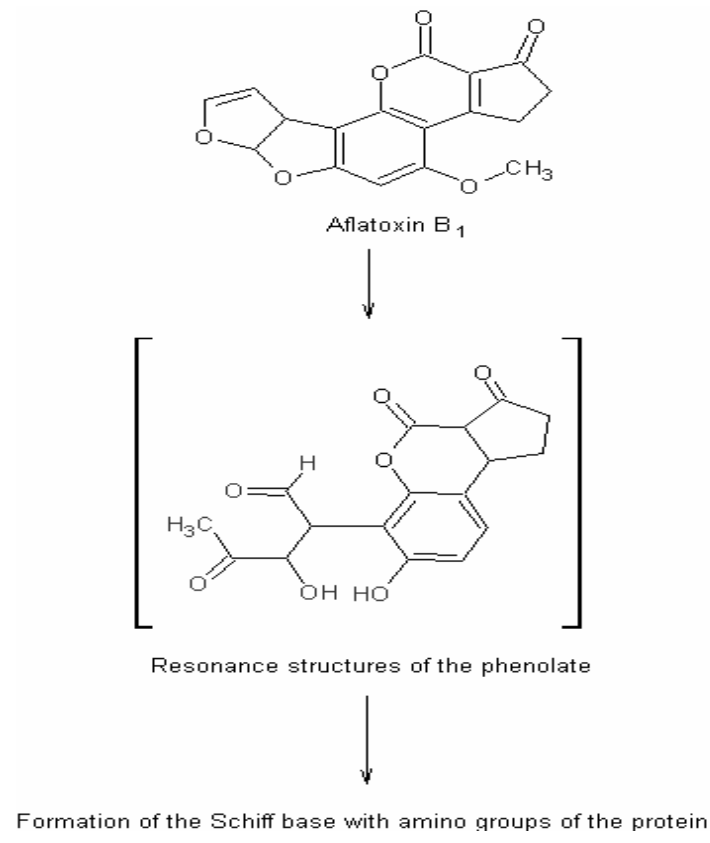

Figure 3 Schiff base formation between protein amino groups and aflatoxin $B_{1}-2,3-$ epoxide (Deshpande, 2002).

\section{CONCLUSIONS}

The biotransformation plays an important role in the biological activity and nature of alfatoxins. The detoxification mechanism involves mechanisms of biotransformation which are known as well. AFB1 represent by far the most toxic of the aflatoxins, and almost all the available information about bioactivity alfatoxins at animal is focused on AFB1 and its metabolites. Also aflatoxin is usually found in high concentration in contaminated food and animal feed.

Vol. XVIII (2014), no. 2 
It is important to note that not all the biotransformation occur of each species and that AFB1 metabolites vary with the species, the type of tissue and the age of the animal. The many of the same dietary factors or other agents known to alter the metabolism of another carcinogens agents similar with AFB1. The activity of the enzymes glutathione-S-transferase (GST) to AFBO suitable an important role in determining the resistance to some rodents AFB1. When a large part of the liver hepatocytes contain increased amounts of $\gamma$-glutamyl transpeptidase as a result of feeding hepatocarcinogenic substances such as AFB1, AFB1 conjugation in the gallbladder contains complex AFB1-Cys-Gly. In later stages of setting up mercapturate AFB1-peptidase activity and $\mathrm{N}$-acetyltransferase. The Mercapturate of AFB1 was detected in the urine of rats and monkeys after administration of AFB1. Metabolism of aflatoxins other than AFB1 was studied and researched with less interest because of their potential toxic and low rate of occurrence.

\section{ACKNOWLEDGEMENTS}

This work was supported by the strategic grant POSDRU/159/1.5/S/133255, Project ID 133255 (2014), co-financed by the European Social Fund within the Sectorial Operational Program Human Resources Development 2007 - 2013.

\section{REFERENCES}

1. Abbas, H., J. Wilkinson, R. Zablotowicz, C. Accinelli, C. Abel, H. Bruns, and M. Weaver. (2009). Ecology of Aspergillus flavus, regulation of aflatoxin production, and management strategies to reduce aflatoxin contamination of corn. Toxin Reviews. 28 (2-3), 142153

2. Abbas, H. K., M. A. Weaver, R. M. Zablotowicz, B. W. Horn, and W. T. Shier. (2005). Relationships between aflatoxin production and sclerotia formation among isolates of Aspergillus section Flavi from the Mississippi Delta. European Journal of Plant Pathology. 112 (3), 283-287

3. Afshar, P., M. Shokrzadeh, S. Kalhori, Z. Babaee, and S. Saeedi Saravi. (2013). Occurrence of Ochratoxin A and Aflatoxin M1 in human breast milk in Sari, Iran. Food Control. 31 (2), 525-529

4. Agag, B. (2004). Mycotoxins in foods and feeds: 1-aflatoxins. Ass. Univ. Bull. Environ. Res. 7 (1), 173-205

5. Ali, S., A. Malik, M. Shahid, and R. Bhargava. (2013). Pulmonary Aspergillosis and Aflatoxins in Chronic Lung Diseases. Mycopathologia. 176 (3-4), 287-294

Vol. XVIII (2014), no. 2 
6. Alinezhad, S., M. Tolouee, A. Kamalzadeh, A. Motalebi, M. Nazeri, M. Yasemi, M. Shams-Ghahfarokhi, R. Tolouei, and M. RazzaghiAbyaneh. (2011). Mycobiota and aflatoxin B1 contamination of rainbow trout (Oncorhinchus mykiss) feed with emphasis to Aspergillus section Flavi. Iranian Journal of fisheries. 10 (3), 363374

7. Allcroft, R., H. Rogers, and G. Lewis. (1966). Metabolism of Aflatoxin in Sheep: Excretion of theMilk Toxin'. Nature. 209 154155

8. Arana, S., V. Alves, M. Sabino, Y. Tabata, S. Nonogaki, M.-L. Zaidan-Dagli, and F. Hernandez-Blazquez. (2014). Immunohistochemical Evidence for Myofibroblast-like Cells Associated with Liver Injury Induced by Aflatoxin B1 in Rainbow Trout (Oncorhynchus mykiss). Journal of comparative pathology. 150 (2), 258-265

9. Bennett, J. W., and M. Klich. (2003). Mycotoxins. Clinical Microbiology Reviews. 16 (3), 497-499

10. Bhatnagar, D., J. Yu, and K. C. Ehrlich. (2002). Toxins of filamentous fungi. Fungal Allergy and Pathogenicity. 81 167-206

11. Bilandžić, N., I. Varenina, and B. Solomun. (2010). Aflatoxin M1 in raw milk in Croatia. Food Control. 21 (9), 1279-1281

12. Blount, W. (1961). Turkey "X" disease. Turkeys. 9 (2), 52-55

13. Campone, L., A. L. Piccinelli, R. Celano, M. Russo, and L. Rastrelli. (2013). Rapid analysis of aflatoxin M1 in milk using dispersive liquid-liquid microextraction coupled with ultrahigh pressure liquid chromatography tandem mass spectrometry. Anal Bioanal Chem. 405 (26), 8645-52

14. Carvalho, K., G. Goncalves, A. Lopes, E. Santos, E. Vargas, and W. Magalhães. (2012). Modelling uncertainty estimation for the determination of aflatoxin M1 in milk by visual and densitometric thin-layer chromatography with immunoaffinity column clean-up. Food Additives \& Contaminants: Part A. 29 (4), 679-693

15. Cavaliere, C., P. Foglia, C. Guarino, F. Marzioni, M. Nazzari, R. Samperi, and A. Laganà. (2006). Aflatoxin M1 determination in cheese by liquid chromatography-tandem mass spectrometry. Journal of Chromatography A. 1135 (2), 135-141

16. Chanda, A., L. V. Roze, S. Kang, K. A. Artymovich, G. R. Hicks, N. V. Raikhel, A. M. Calvo, and J. E. Linz. (2009). A key role for vesicles in fungal secondary metabolism. Proceedings of the National Academy of Sciences. 106 (46), 19533-19538

17. Chen, J., K. Chen, S. Yuan, X. Peng, J. Fang, F. Wang, H. Cui, Z. Chen, J. Yuan, and Y. Geng. (2013). Effects of aflatoxin B1 on

Vol. XVIII (2014), no. 2 
oxidative stress markers and apoptosis of spleens in broilers. Toxicology and industrial health. 0748233713500819

18. Cleveland, T. E., P. F. Dowd, A. E. Desjardins, D. Bhatnagar, and P. J. Cotty. (2003). United States Department of Agriculture Agricultural Research Service research on pre-harvest prevention of mycotoxins and mycotoxigenic fungi in US crops. Pest Management Science. 59 (6-7), 629-642

19. Creppy, E. E. (2002). Update of survey, regulation and toxic effects of mycotoxins in Europe. Toxicology Letters. 127 (1-3), 19-28

20. Cucci, C., A. Mignani, C. Dall'Asta, R. Pela, and A. Dossena. (2007). A portable fluorometer for the rapid screening of M1 aflatoxin. Sensors and Actuators B: Chemical. 126 (2), 467-472

21. David , J.P., F. Peter Guengerich, and J. O. Miners. (2005). "Phase I and Phase II" drug metabolism: terminology that we should phase out? Drug metabolism reviews. 37 (4), 575-580

22. De Iongh, H., R. Vles, and J. Van Pelt. (1964). Milk of mammals fed an aflatoxin-containing diet. Nature. 202 466-467

23. Deshpande, S.(2002). Handbook of food toxicology. Translated by CRC Press. Original edition.

24. Desjardins, A. E.(2006). Fusarium mycotoxins: chemistry, genetics, and biology.Translated by American Phytopathological Society (APS Press). Original edition.

25. Diaz, G. J., H. W. Murcia, and R. Guevara-González. (2011). Biotransformation of aflatoxin B1 and its relationship with the differential toxicological response to aflatoxin in commercial poultry species. Aflatoxins-Biochem. Mol. Biol. Rijeka, Croacia: InTech.

26. Eaton, D. L., T. K. Bammler, and E. J. Kelly. (2001). Interindividual differences in response to chemoprotection against aflatoxin-induced hepatocarcinogenesis: Implications for human biotransformation enzyme polymorphisms. Biological Reactive Intermediates Vi. 500 559-576

27. Eaton, D. L., and E. P. Gallagher. (1994). Mechanisms of aflatoxin carcinogenesis. Annual review of pharmacology and toxicology. 34 (1), 135-172

28. Ehrlich, K. C., B. G. Montalbano, and P. J. Cotty. (2003). Sequence comparison of aflR from different Aspergillus species provides evidence for variability in regulation of aflatoxin production. Fungal Genetics and Biology. 38 (1), 63-74

29. E. Commission.(2006).Commission Regulation (EC) No 1881/2006 of 19 December 2006 setting maximum levels for certain contaminants in foodstuffs.Bruxelles: (C) European Union, 1998-2014

Vol. XVIII (2014), no. 2 
30. Fallah, A. A. (2010). Assessment of aflatoxin M1 contamination in pasteurized and UHT milk marketed in central part of Iran. Food and Chemical Toxicology. 48 (3), 988-991

31. Fallah, A. A., T. Jafari, A. Fallah, and M. Rahnama. (2009). Determination of aflatoxin M1 levels in Iranian white and cream cheese. Food and chemical toxicology. 47 (8), 1872-1875

32. Fetaih, H. A., A. A. Dessouki, A. A. Hassanin, and A. S. Tahan. (2014). Toxopathological and Cytogenetic effects of Aflatoxin B1 (AFB1) on pregnant rats. Pathology-Research and Practice.

33. Fiala, J. L., P. A. Egner, N. Wiriyachan, M. Ruchirawat, K. H. Kensler, G. N. Wogan, J. D. Groopman, R. G. Croy, and J. M. Essigmann. (2011). Sulforaphane-mediated reduction of aflatoxin B1-N7-guanine in rat liver DNA: impacts of strain and sex. Toxicological Sciences. 121 (1), 57-62

34. Gallagher, E., L. Wienkers, P. Stapleton, K. Kunze, and D. Eaton. (1994). Role of human microsomal and human complementary DNA-expressed cytochromes P4501A2 and P4503A4 in the bioactivation of aflatoxin B1. Cancer research. 54 (1), 101-108

35. Gan, N., J. Zhou, P. Xiong, F. Hu, Y. Cao, T. Li, and Q. Jiang. (2013). An ultrasensitive electrochemiluminescent immunoassay for aflatoxin M1 in milk, based on extraction by magnetic graphene and detection by antibody-labeled CdTe quantumn dots-carbon nanotubes nanocomposite. Toxins (Basel). 5 (5), 865-83

36. Georgianna, D. R., and G. A. Payne. (2009). Genetic regulation of aflatoxin biosynthesis: from gene to genome. Fungal Genetics and Biology. 46 (2), 113-125

37. Gross-Steinmeyer, K., and D. L. Eaton. (2012). Dietary modulation of the biotransformation and genotoxicity of aflatoxin B1. Toxicology. 299 (2), 69-79

38. Guengerich, F. P., W. W. Johnson, T. Shimada, Y.-F. Ueng, H. Yamazaki, and S. Langouët. (1998). Activation and detoxication of aflatoxin B1. Mutation Research/Fundamental and Molecular Mechanisms of Mutagenesis. 402 (1), 121-128

39. Gürbay, A., S. A. Sabuncuoğlu, G. Girgin, G. Şahin, Ş. Yiğit, M. Yurdakök, and G. Tekinalp. (2010). Exposure of newborns to aflatoxin M1 and B 1 from mothers' breast milk in Ankara, Turkey. Food and chemical toxicology. 48 (1), 314-319

40. Han, Z., Y. Zheng, L. Luan, Z. Cai, Y. Ren, and Y. Wu. (2010). An ultra-high-performance liquid chromatography-tandem mass spectrometry method for simultaneous determination of aflatoxins B1, B2, G1, G2, M1 and M2 in traditional Chinese medicines. Analytica chimica acta. 664 (2), 165-171

Vol. XVIII (2014), no. 2 
41. Hashemi, M., Z. Taherimaslak, and S. Rashidi. (2014). Enhanced spectrofluorimetric determination of aflatoxin M1 in liquid milk after magnetic solid phase extraction. Spectrochim Acta A Mol Biomol Spectrosc. 128 583-90

42. He, J., K. Zhang, D. Chen, X. Ding, G. Feng, and X. Ao. (2013). Effects of maize naturally contaminated with aflatoxin B1 on growth performance, blood profiles and hepatic histopathology in ducks. Livestock Science. 152 (2), 192-199

43. Herzallah, S., K. Alshawabkeh, and A. A. Fataftah. (2008). Aflatoxin Decontamination of Artificially Contaminated Feeds by Sunlight, $\gamma$ Radiation, and Microwave Heating. The Journal of Applied Poultry Research. 17 (4), 515-521

44. Huang, L., N. Zheng, B. Zheng, F. Wen, J. Cheng, R. Han, X. Xu, S. $\mathrm{Li}$, and J. Wang. (2014). Simultaneous determination of aflatoxin M 1 , ochratoxin A, zearalenone and $\alpha$-zearalenol in milk by UHPLCMS/MS. Food chemistry. 146 242-249

45. Hussain, Z., M. Z. Khan, A. Khan, I. Javed, M. K. Saleemi, S. Mahmood, and M. R. Asi. (2010). Residues of aflatoxin B1 in broiler meat: Effect of age and dietary aflatoxin B1 levels. Food and Chemical Toxicology. 48 (12), 3304-3307

46. IARC Working Group on the Evaluation of Carcinogenic Risks to Humans, World Health Organization, and International Agency for Research on Cancer (2002). Some Traditional Herbal Medicines, Some Mycotoxins, Naphthalene and Styrene: Some traditional herbal medicines, some mycotoxins, naphthalene and styrene.Translated by World Health Organization. Original edition.

47. Kamkar, A. (2006). A study on the occurrence of aflatoxin M1 in Iranian Feta cheese. Food Control. 17 (10), 768-775

48. Kanungo, L., S. Pal, and S. Bhand. (2011). Miniaturised hybrid immunoassay for high sensitivity analysis of aflatoxin M1 in milk. Biosensors and Bioelectronics. 26 (5), 2601-2606

49. Kav, K., R. Col, and K. Kaan Tekinsen. (2011). Detection of aflatoxin M1 levels by ELISA in white-brined Urfa cheese consumed in Turkey. Food Control. 22 (12), 1883-1886

50. Kensler, T. W., B. D. Roebuck, G. N. Wogan, and J. D. Groopman. (2011). Aflatoxin: a 50-year odyssey of mechanistic and translational toxicology. Toxicological Sciences. 120 (suppl 1), S28-S48

51. Ketney, O., T. Ovidiu, and T. Mihaela (2010). Variation of aflatoxin M1 in milk at different doses of ultraviolet radiation. In Integrated systems for agri-food production (SIPA 11): ISBN 978-615-5097-26$3^{\wedge}, 2010$.

Vol. XVIII (2014), no. 2 
52. Kirby, G., C. Wolf, G. Neal, D. Judah, C. Henderson, P. Srivatanakul, and C. Wild. (1993). In vitro metabolism of aflatoxin B1 by normal and tumorous liver tissue from Thailand. Carcinogenesis. 14 (12), 2613-2620

53. Klich, M. A. (2002). Biogeography of Aspergillus species in soil and litter. Mycologia. 94 (1), 21-27

54. Klich, M. A. (2007). Aspergillus flavus: the major producer of aflatoxin. Molecular plant pathology. 8 (6), 713-722

55. Kumar, M., V. Verma, R. Nagpal, A. Kumar, P. Behare, B. Singh, and P. Aggarwal. (2012). Anticarcinogenic effect of probiotic fermented milk and chlorophyllin on aflatoxin-B1-induced liver carcinogenesis in rats. British Journal of Nutrition. 107 (07), 10061016

56. Larsson, P., and H. Tjälve. (2000). Intranasal instillation of aflatoxin B1 in rats: bioactivation in the nasal mucosa and neuronal transport to the olfactory bulb. Toxicological Sciences. 55 (2), 383-391

57. Li, P., Q. Zhang, and W. Zhang. (2009). Immunoassays for aflatoxins. TrAC trends in analytical chemistry. 28 (9), 1115-1126

58. Li, P., Y. Zhang, H.-t. Lei, H. Wang, Z.-1. Xu, Y.-d. Shen, Y.-m. Sun, J. Pang, and J.-y. Yang. (2014). Development of chemiluminescent enzyme immunoassay for the determination of aflatoxin M1 in milk products. Food and Agricultural Immunology. (ahead-of-print), 1-13

59. Logrieco, A., G. Mule, A. Moretti, and A. Bottalico. (2002). Toxigenic Fusarium species and mycotoxins associated with maize ear rot in Europe. European Journal of Plant Pathology. 108 (7), $597-609$

60. Machida, M., K. Asai, M. Sano, T. Tanaka, T. Kumagai, G. Terai, K.-I. Kusumoto, T. Arima, O. Akita, and Y. Kashiwagi. (2005). Genome sequencing and analysis of Aspergillus oryzae. Nature. 438 (7071), 1157-1161

61. Magnoli, A., M. Monge, R. Miazzo, L. Cavaglieri, C. Magnoli, C. Merkis, A. Cristofolini, A. Dalcero, and S. Chiacchiera. (2011). Effect of low levels of aflatoxin B1 on performance, biochemical parameters, and aflatoxin B1 in broiler liver tissues in the presence of monensin and sodium bentonite. Poultry science. 90 (1), 48-58

62. Micheli, L., R. Grecco, M. Badea, D. Moscone, and G. Palleschi. (2005). An electrochemical immunosensor for aflatoxin M1 determination in milk using screen-printed electrodes. Biosensors and Bioelectronics. 21 (4), 588-596

63. Nguyen, B. H., L. D. Tran, Q. P. Do, H. L. Nguyen, N. H. Tran, and P. X. Nguyen. (2013). Label-free detection of aflatoxin M1 with

Vol. XVIII (2014), no. 2 
electrochemical Fe3O4 polyaniline-based aptasensor. Materials Science and Engineering: C. 33 (4), 2229-2234

64. Paniel, N., A. Radoi, and J.-L. Marty. (2010). Development of an electrochemical biosensor for the detection of aflatoxin M1 in milk. Sensors. 10 (10), 9439-9448

65. Park, D. L. (2002). "Effect of processing on aflatoxin." In Mycotoxins and Food Safety, 173-179. Springer.

66. Rameil, S., P. Schubert, P. Grundmann, R. Dietrich, and E. Märtlbauer. (2010). Use of 3-(4-hydroxyphenyl) propionic acid as electron donating compound in a potentiometric aflatoxin $\mathrm{M}$ 1immunosensor. Analytica chimica acta. 661 (1), 122-127

67. Raphaël, K. J., N. Ferdinand, T. Hervé, T. C. D'alex, S. Y. Roméo, T. Alexis, and G. G. J. Benoit. (2014). Effect of Biocharcoals on Hematological, Serum Biochemical and Histological Parameters in Broiler Chickens Fed Aflatoxin B1-Contaminated Diets. Journal of Animal Science Advances. 4 (7),

68. Richard, J. L. (2007). Some major mycotoxins and their mycotoxicoses-An overview. International Journal of Food Microbiology. 119 (1-2), 3-10

69. Sarter, S., and N. Zakhia. (2004). Chemiluminescent and bioluminescent assays as innovative prospects for mycotoxin determination in food and feed. Luminescence. 19 (6), 345-51

70. Schmidt-Heydt, M., A. Abdel-Hadi, N. Magan, and R. Geisen. (2009). Complex regulation of the aflatoxin biosynthesis gene cluster of Aspergillus flavus in relation to various combinations of water activity and temperature. International journal of food microbiology. 135 (3), 231-237

71. Shyamal, S., P. Latha, S. Suja, V. Shine, G. Anuja, S. Sini, S. Pradeep, P. Shikha, and S. Rajasekharan. (2010). Hepatoprotective effect of three herbal extracts on aflatoxin B1-intoxicated rat liver. Singapore medical journal. 51 (4), 326-331

72. Troxel, C. M., A. P. Reddy, P. E. O'Neal, J. D. Hendricks, and G. S. Bailey. (1997). In VivoAflatoxin B1Metabolism and Hepatic DNA Adduction in Zebrafish (Danio rerio). Toxicology and Applied Pharmacology. 143 (1), 213-220

73. Vdovenko, M. M., C.-C. Lu, F.-Y. Yu, and I. Y. Sakharov. (2014). Development of ultrasensitive direct chemiluminescent enzyme immunoassay for determination of aflatoxin M1 in milk. Food chemistry. 158 310-314

74. Wan, X., Z. Yang, W. Yang, S. Jiang, G. Zhang, S. Johnston, and F. Chi. (2013). Toxicity of increasing aflatoxin B1 concentrations from

Vol. XVIII (2014), no. 2 
contaminated corn with or without clay adsorbent supplementation in ducklings. Poultry science. 92 (5), 1244-1253

75. Wang, Y., X. Liu, C. Xiao, Z. Wang, J. Wang, H. Xiao, L. Cui, Q. Xiang, and T. Yue. (2012). HPLC determination of aflatoxin M1 in liquid milk and milk powder using solid phase extraction on OASIS HLB. Food Control. 28 (1), 131-134

76. Wu, F., J. D. Groopman, and J. J. Pestka. (2014). Public health impacts of foodborne mycotoxins. Annual review of food science and technology. 5 351-372

77. Wu, F., and H. Guclu. (2012). Aflatoxin regulations in a network of global maize trade. PloS one. 7 (9), e45151

78. Yabe, K., and H. Nakajima. (2004). Enzyme reactions and genes in aflatoxin biosynthesis. Applied Microbiology and Biotechnology. 64 (6), 745-755

79. Yabe, K., M. Nakamura, and T. Hamasaki. (1999). Enzymatic formation of G-group aflatoxins and biosynthetic relationship between G- and B-group aflatoxins. Applied and Environmental Microbiology. 65 (9), 3867-3872

80. Yu, J. (2003). "Genetics and biochemistry of mycotoxins synthesis." In Handbook of Fungal Biotechnology, edited by D. K. Arora. Taylor \& Francis.

81. Yunus, A. W., E. Razzazi-Fazeli, and J. Bohm. (2011). Aflatoxin B1 in affecting broiler's performance, immunity, and gastrointestinal tract: A review of history and contemporary issues. Toxins. 3 (6), 566-590

Vol. XVIII (2014), no. 2 